\title{
DIREITO, SOCIEDADE E COMUNICAÇÃO: UM EXAME DO ANTEPROJETO DE LEI DA MÍDIA DEMOCRÁTICA NO BRASIL
}

\author{
Danilo Rothberg, Carlo José Napolitano \& Tatiana Stroppa
}

\begin{abstract}
Resumo
Este artigo contextualiza a dinâmica dos movimentos sociais pela democratização da mídia no Brasil contemporâneo, que culminou na formulação de um anteprojeto de lei que, desde o ano de 2012, busca coletar 1,4 milhão de assinaturas para ingressar no Parlamento como projeto de lei de iniciativa popular. Analisamos os pontos fortes e aspectos potencialmente controversos do anteprojeto, à luz de dois critérios: um determinado pela normatividade existente em função do arcabouço constitucional brasileiro, e outro trazido pela comparação com os aspectos normativos existentes na União Europeia. De forma geral, o anteprojeto pode ser caracterizado por inovações relevantes, mas imprecisões conceituais e impactos potenciais de complexa administração, que devem enfrentar grande resistência de setores hegemônicos, podem dificultar o suporte a artigos específicos, tanto na fase de busca de assinaturas quanto em uma eventual tramitação no Parlamento.
\end{abstract}

\section{Palavras-chave}

Regulação de mídia; radiodifusão; projeto de lei; participação política

\section{INTRODUÇÃo}

O percurso de fortalecimento dos movimentos sociais pela democratização das comunicações no Brasil teve, em dezembro de 2009, um ponto crucial com a realização da Conferência Nacional de Comunicação, promovida pelo Ministério das Comunicações. Ainda na esteira do processo desencadeado pela conferência, a campanha "Para expressar a liberdade", lançada em agosto em 2012 e liderada pelo Fórum Nacional pela Democratização da Comunicação (FNDC), busca 1,4 milhão de assinaturas para sustentar a proposição de um projeto de lei de iniciativa popular à Câmara dos Deputados para a regulação da matéria.

Após dois anos de seu lançamento, a coordenação da campanha estima que já foi possível coletar cerca de 150 mil assinaturas, ou seja, pouco mais de $10 \%$ do total pretendido'. Se mantido o ritmo, serão necessários outros nove anos para a consecução de sua meta, prazo não necessariamente compatível com as crescentes demandas sociais sobre o tema.

Este artigo contextualiza a formulação do anteprojeto de lei da mídia democrática e indica seus pontos fortes e aspectos potencialmente controversos, à luz de dois critérios: um determinado pela normatividade existente em função do arcabouço constitucional brasileiro, e outro trazido pela comparação com os aspectos normativos existentes na 
União Europeia, considerada aqui como referência em função de seu significativo avanço na obtenção de consenso social pela regulação de mídia. O objetivo é apresentar um balanço entre fatores que podem contribuir para fazer avançar a obtenção de apoio ao anteprojeto, e fatores que podem retardá-lo.

De forma geral, o anteprojeto pode ser caracterizado por inovações oportunas e relevantes diante do cenário constitucional brasileiro e das recomendações vigentes no contexto europeu. Mas imprecisões conceituais e impactos potenciais de complexa administração, que devem enfrentar enorme resistência de setores hegemônicos, podem dificultar o suporte a artigos específicos, tanto na fase de busca de assinaturas quanto em uma eventual tramitação no Parlamento, se a campanha for bem-sucedida e a proposta ingressar na Casa como projeto de lei iniciativa popular.

Em função de seu propósito, o artigo está dividido em três etapas. A primeira oferece breves teorizações fundamentais. A segunda analisa os seis capítulos do anteprojeto de lei em relação aos princípios normativos selecionados e indica pontos em aberto. Na terceira, breves conclusões sintetizam as contribuições do texto ao avanço do conhecimento sobre as propostas decorrentes da mobilização social em torno da democratização da comunicação no Brasil.

\section{TeORIZAÇões PeRTINENTES}

É típica do sistema jurídico brasileiro a constitucionalização de políticas públicas. A Carta “contém normas ditas 'programáticas' - isto é, normas que preveem objetivos a serem alcançados por meio de políticas públicas [...] e comandos que explicitam valores a serem perseguidos pelo legislador infraconstitucional" (Coutinho, 2013, p. 190). Ao lastrear a definição de tarefas, a divisão de competências e a articulação das relações jurídicas dentro do próprio setor público ou fora dele, o Direito estabelece o arranjo institucional das políticas públicas.

A Constituição (1988) determina direitos relacionados à liberdade de expressão, de informação, de opinião, de criação artística, a preservação do sigilo da fonte e o direito de resposta e afirma a competência privativa da União para legislar sobre radiodifusão, de modo a estabelecer as linhas gerais do arranjo institucional relativo às políticas públicas de comunicação social. O quadro se completa com os artigos 220 a 224, que são vocalizadores de demandas e objetivos a serem alcançados via políticas públicas da área: liberdade de manifestação do pensamento, de criação, expressão e informação; proibição de censura, monopólios e oligopólios; prioridade na produção e programação das emissoras de rádio e TV para finalidades educativas, artísticas, culturais e informativas, para a promoção da cultura nacional e regional.

Mas vários temas constitucionalmente previstos dependem de regulação via legislação infraconstitucional, em particular no campo da comunicação, que requer a edição de dispositivos para matérias legais que incluem: 1. Diversões e espetáculos públicos, que devem se sujeitar à classificação indicativa e divulgar informações sobre seu conteúdo, as faixas etárias a que não se recomendam, e locais e horários adequados de 
apresentação; 2. Mecanismos que garantam à pessoa e à família a possibilidade de se defender de programas que contrariem valores éticos e sociais, e da propaganda de produtos, práticas e serviços nocivos à saúde e ao meio ambiente; 3. Propaganda de tabaco, bebidas alcoólicas, agrotóxicos, medicamentos e terapias; 4. Regionalização da produção cultural, artística e jornalística; 5. Meios de radiodifusão; 6. Participação de capital estrangeiro na propriedade de empresas da área; 7. Criação do Conselho de Comunicação Social, órgão auxiliar do Congresso Nacional.

Destas sete exigências constitucionais, apenas três foram regulamentadas: a lei 9.294/1996 restringe a propaganda de tabaco e bebidas; a lei 10.610/2002 permite a participação de capital estrangeiro em até 30\% do capital das empresas da área; e a lei 8.389/1991 criou o Conselho de Comunicação Social. E, das três regulamentadas, uma ainda não gerou as consequências esperadas, já que o Conselho de Comunicação Social não tem apresentado uma atuação efetiva (Simis, 2010). Oligopólios e monopólios seguem intocados, no topo de um longo percurso no qual as concessões foram moeda de troca para conquista de apoio político, conforme largamente documentado (Intervozes, 2008; Lima, 2011; Pieranti, 2006; Pieranti \& Martins, 2008; Ramos \& Santos, 2007). Isso a despeito da farta evidência dos impactos positivos da regulação de mídia para o fortalecimento da democracia, originados inclusive da Organização das Nações Unidas através da Unesco (Mendel \& Salomon, 2011a, 2011b; Unesco, 2010).

Diante da escassez regulatória da comunicação, aparatos, instituições e instrumentos de defesa dos direitos humanos são eventualmente empregados no Brasil como solução substitutiva por setores que atuam na proteção contra conteúdos midiáticos. Este foi o caso, por exemplo, do caso histórico da suspensão da programação de uma emissora de TV aberta em 2005 e consequente imposição, pelo Ministério Público Federal, da exibição de programas educativos produzidos por organizações sociais, como punição à emissora pela veiculação regular de um programa considerado uma violação de direitos fundamentais (Intervozes, 2007).

A primeira versão do Programa Nacional de Direitos Humanos, de 1996, trouxe metas para os direitos civis e políticos. A segunda versão, de 2002, incluiu direitos econômicos, sociais e culturais. A terceira, de 2009, amplia o escopo em direção à consolidação das disposições políticas sobre o tema: apesar de editados em governos diferentes, os planos podem ser considerados, "antes de medidas governamentais, políticas de Estado" (Adorno, 2010, p. 9), o que ainda lhes confere constitucionalidade, conforme Piovesan (2010).

A terceira versão do Programa Nacional de Direitos Humanos, em sua Diretriz 22, Eixo V (Educação e Cultura em Direitos Humanos), propõe ao Estado o objetivo estratégico de "promover o respeito aos Direitos Humanos nos meios de comunicação e o cumprimento de seu papel na promoção da cultura em Direitos Humanos", através da "criação de marco legal, nos termos do artigo 221 da Constituição, estabelecendo o respeito aos Direitos Humanos nos serviços de radiodifusão (rádio e televisão) concedidos, permitidos ou autorizados", conforme Decreto 7.037 (2009).

O Plano contribui para ocupar um vazio denunciado por instituições como partidos políticos e confederações de trabalhadores nos termos de Ações Diretas de 
Inconstitucionalidade por Omissão almejando a declaração, pelo Supremo Tribunal Federal, de inconstitucionalidade da omissão do Congresso Nacional em não legislar sobre as matérias constantes em artigos constitucionais sobre a matéria ${ }^{2}$. Persiste a demanda por uma nova lei geral para as comunicações no Brasil, a fim de substituir o obsoleto Código Brasileiro de Telecomunicações - lei 4.117/1962.

Este cenário corrobora a pertinência da proposta de criação de um marco legal, como ambiciona o anteprojeto de lei de iniciativa popular da comunicação social eletrônica, que ainda se insere na recente trajetória de mobilização social e participação política intensificada pela $1^{\circ}$ Conferência Nacional de Comunicação, realizada pelo governo federal em dezembro de 2009, em Brasília.

Participaram 1.800 delegados, indicados em etapas estaduais preparatórias, representando organizações da sociedade civil empresarial (40\% do total), da sociedade civil não empresarial (40\%) e das três esferas de governo (20\%) (Ministério das Comunicações, 2010). Os setores que militam pela democratização da comunicação esperavam que suas propostas fossem incorporadas ao processo de formulação de políticas públicas, o que ainda não ocorreu (Dantas \& Neiva, 2014).

A intensificação das reivindicações de participação também é indicada pela composição progressiva de conselhos estaduais de comunicação, que aos poucos contribuem para situar a área como objeto de política pública (Lima, 2013).

Neste sentido, as pressões pela democratização na mídia no Brasil se inscrevem na trajetória de luta de movimentos sociais que ganharam força com a estabilidade democrática e passaram a comportar uma pluralidade de bandeiras e a se exprimir por meio de identidades diversificadas, nem sempre organizadas com a unicidade típica dos movimentos das décadas de 1980 e 1990, mas também em busca de influência sobre o poder político (Gohn, 2014).

Os setores mobilizados por mudanças nas leis de mídia se organizam através de redes sociais que funcionam como formas de amplificação de suas visões sobre os problemas a serem enfrentados, em uma luta simbólica pela propagação de enquadramentos que sofre com os estereótipos usuais em um país de redemocratização recente, no qual a censura foi exercida pelo Estado e a liberdade de empresa toma o lugar da liberdade de imprensa (Carlos, 2011; Leal Filho, 2006; Nunes, 2013).

Além disso, cabe realçar que a busca por um ambiente que assegure a pluralidade de fontes de informação e de opinião e que combata a concentração dos meios de comunicação nas mãos de poucos grupos tem sido constante na agenda de países da América Latina cujos governos têm buscado a regulamentação da mídia.

Nesse cenário, a aprovação, na Argentina, da Lei de Serviços de Comunicação Audiovisual (Lei $n^{\circ}$ 26.522, de outubro de 2009), conhecida como Ley de Medios, é um exemplo expressivo. A lei estabelece a regulação, a fiscalização, o fomento e a diversificação das atividades informativas e culturais, coibindo monopólios e oligopólios ao fixar quem pode ser concessionário de emissoras de rádio e de televisão e quais são os

\footnotetext{
${ }^{2}$ A tramitação das ações, movidas pela Confederação Nacional dos Trabalhadores em Comunicações e Publicidade e pelo Partido Socialismo e Liberdade (Psol), pode ser consultada em http://www.stf.jus.br/portal/processo/verProcessoAndamento. asp? incidente $=4003096$.
} 
limites para o número de licenças controladas por um único grupo e os limites de propriedade cruzada de meios (Lima, 2014; Moraes, 2014).

A Ley de Medios teve a constitucionalidade de seus artigos 41 e 45, 48 e 161 questionada na Justiça pelos grupos econômicos mais duramente afetados pelas modificações legais. Tais artigos dispõem, respectivamente, sobre: transferência das concessões; a multiplicidade de concessões; impossibilidade de se evocar o "regime de multiplicidade de concessões" e a obrigatoriedade de adequação à lei por parte daqueles grupos já detentores de concessões. Em outubro de 2013, a Suprema Corte Argentina declarou a constitucionalidade de todos os artigos questionados na ação (Lima, 2014).

Além da Ley de Medios, devem ser incluídas, como instrumentos de combate à concentração da propriedade dos meios de comunicação no setor privado aprovados nos últimos 15 anos, a Lei Orgânica de Comunicação do Equador, de junho de 2013, a Lei Orgânica de Telecomunicações da Venezuela, aprovada em março de 2000, a Lei Geral de Telecomunicações, Tecnologias de Informação e Comunicação da Bolívia, de agosto de 2011, e as Leis de Radiodifusão Comunitária e de Serviços Audiovisuais aprovadas em dezembro de 2013 no Uruguai. Esta lista deveria seguir com outros exemplos, mas isto excederia os propósitos do presente artigo.

\section{CARACTERIZAÇÃo E ANÁLISE DO ANTEPROJETO DE LEI}

A campanha "Para expressar a liberdade" é apresentada em sua página web oficial como "iniciativa de centenas de entidades da sociedade civil que acreditam que uma nova lei geral de comunicações é necessária" (FNDC, 2012). A iniciativa da campanha é do FNDC - Fórum Nacional pela Democratização da Comunicação, criado em 1991 como movimento social e institucionalizado em 1995 (FNDC, 2014a). Na página www. paraexpressaraliberdade.org.br há informações sobre como contribuir com a divulgação. Em outubro de 2014, havia 25 pontos de coleta de assinaturas para o anteprojeto de lei em seis Estados e no Distrito Federal, em sua maioria sedes de sindicatos, mas também TVs e associações comunitárias, livrarias e bares. Mas na página também está disponível um "kit coleta", para voluntários em geral buscarem adesão em quaisquer espaços públicos ou privados (FNDC, 2014b).

Segundo o artigo 61 da Constituição Federal do Brasil:

a iniciativa popular pode ser exercida pela apresentação à Câmara dos Deputados de projeto de lei subscrito por, no mínimo, um por cento do eleitorado nacional, distribuído pelo menos por cinco Estados, com não menos de três décimos por cento dos eleitores de cada um deles (Constituição Federal, 1988).

Em agosto de 2014, o número de eleitores no país era de 142.822.046, o que requer a coleta de 1,42 milhão de assinaturas para uma proposta ingressar na Câmara através deste dispositivo, respeitadas as demais exigências de proporcionalidade territorial (TSE, 2014). 
O anteprojeto de lei de iniciativa popular da comunicação social eletrônica objetiva regulamentar os artigos 5, 21, 22, 220 a 224 da Constituição Federal, e está estruturado em seis capítulos, a saber: 1. Definições sobre o objeto da lei; 2. Princípios e objetivos da comunicação social eletrônica; 3. Organização dos serviços e estabelecimento de critérios de outorga; 4. Mecanismos para impedir a concentração no setor; 5 . Mecanismos de incentivo à diversidade; 6 . Definição de órgãos reguladores e criação do Conselho Nacional de Políticas de Comunicação.

Do anteprojeto verifica-se uma tentativa de unificação da legislação relacionada à comunicação social. Percebe-se a intenção de regular a comunicação pelo objeto, independente do meio. Essa conclusão se extrai da leitura e interpretação de seu artigo $2^{\circ}$, inciso I, do capítulo 1, que define comunicação social eletrônica como toda "atividade de telecomunicação ou de radiodifusão que possibilitem a entrega de programação audiovisual ou de rádio em qualquer plataforma" (FNDC, 2014b), não havendo distinção em relação ao meio de transmissão.

Esta inovação é relevante porque abole do sistema jurídico brasileiro a diversidade de leis regulamentadoras da matéria, problema apontado pela literatura, que decorreria da "separação (...) entre o direito das telecomunicações e o direito da radiodifusão", segundo Sundfeld (2004, pp. 115-116). Normas constitucionais, Ministério das Comunicações, Congresso Nacional e o Código Brasileiro de Telecomunicações de 1962 se sobrepõem em um cenário ao qual a Anatel - Agência Nacional de Telecomunicações sobreveio com a gestão técnica do espectro e das estações. "Há (...) autonomia institucional e normativa da regulação da radiodifusão relativamente à de telecomunicações: leis e estruturas de mercado diferentes, concepções jurídicas incompatíveis, autoridade reguladora distinta, etc", para Sundfeld (2004, pp. 115-116), o que compõe um ambiente regulatório incompatível com a convergência e a digitalização de serviços.

A necessidade de regular a atividade da comunicação social pelo conteúdo se deve ao fato de que, como indica Cordeiro (2004, p. 12), "na radiodifusão tradicional, na efectuada por cabo, por satélite ou pela Internet (...), estamos, em todas elas, perante modalidades de uma mesma realidade, havendo variações meramente quantitativas".

No âmbito da União Europeia, a regulação assume o mesmo pressuposto, de acordo com a Diretiva 2010/13. Para "evitar distorções da concorrência, aumentar a segurança jurídica (...) e facilitar a criação de um espaço único da informação", torna-se necessária a aplicação de um "conjunto mínimo de regras coordenadas" a todos os serviços de "comunicação social audiovisual, tanto à radiodifusão televisiva (...) como aos serviços de comunicação social audiovisual a pedido (...)" (Directiva, 2010/13, p. 95/2), ou seja, o que no Brasil se considera serviço especializado on demand, seja ele comercializado por radiodifusão, cabo ou internet, segundo os considerandos 11 e 27 da Diretiva.

A inovação do capítulo 2 reside na definição, via lei infraconstitucional, dos conceitos relacionados à complementaridade da radiodifusão, em sistema privado, público e estatal. A carência de regulação e consequente indefinição legal desses conceitos podem gerar insegurança jurídica. $O$ anteprojeto de lei, se aprovado, supriria essa lacuna legal.

De acordo com o anteprojeto, o sistema tripartite seria assim definido: o sistema público compreende as emissoras de caráter público ou associativo-comunitário, 
geridas de maneira participativa, a partir da possibilidade de acesso dos cidadãos a suas estruturas dirigentes e submetidas a regras democráticas de gestão, desde que sua finalidade principal não seja a transmissão de atos dos poderes Executivo, Legislativo e Judiciário. O sistema privado abrange as emissoras de propriedade de entidades privadas em que a natureza institucional e o formato de gestão sejam restritos, sejam estas entidades de finalidade lucrativa ou não. O sistema estatal abrange as emissoras cuja finalidade principal seja a transmissão de atos dos poderes Executivo, Legislativo e Judiciário e aquelas controladas por instituições públicas vinculadas aos poderes do Estado nas três esferas da Federação que não atendam aos requisitos de gestão definidos para o sistema público.

A ideia de adoção do sistema tripartite nas concessões de rádio e TV foi concebida durante o processo constituinte (1987-1988). O relatório da Comissão Temática da Família, Educação, Cultura e Esportes, Ciência e Tecnologia e Comunicação já sustentava que o comando estatal das atividades privadas, que vigorou no Brasil no período autoritário, deveria ser superado, uma vez que "o País pretendeu fazer um desenvolvimento capitalista rápido, conseguiu, porém, contra o seu povo, à custa do seu povo". Nesse percurso, teria surgido a "destinação praticamente exclusiva dos meios de comunicação social a instituições do capital" com "cerca de 95\% das concessões em mãos do capital e perto de 5\% em mãos do Estado", e assim protestava o relator da comissão: "ora, uma democracia não possui apenas o capital e o Estado como instituições sociais" (SEEP, 2008, p. 178).

Ademais, o capítulo 2 apresenta-se coerente com as determinações vigentes na União Europeia. "Os serviços de comunicação social audiovisual são, simultaneamente, serviços culturais e serviços económicos", segundo os considerandos 5 e 8 da Diretiva 2010/13, que situa a "importância crescente de que se revestem para as sociedades, a democracia - garantindo designadamente a liberdade de informação, a diversidade de opiniões e o pluralismo dos meios de comunicação social" (Directiva, 2010/13, pp. 95/1) como justificativa para a aplicação de regras específicas àqueles serviços; torna-se fundamental evitar circunstâncias "que possam prejudicar a liberdade de circulação e de comércio das emissões televisivas ou que possam promover a criação de posições dominantes susceptíveis de conduzir a restrições ao pluralismo e à liberdade da informação (...)" (Directiva, 2010/13, pp. 95/2). Note-se que sob tais circunstâncias inclui-se a exploração majoritária da radiodifusão por um único sistema, seja ele estatal, público ou comercial. Ou seja, torna-se imprescindível, inclusive, a adoção de regulação adequada para impedir que o poder econômico seja o vetor predominante, sob risco de prejuízo à democracia.

O capítulo 3 inova ao atribuir competência à Anatel para concessão e administração de outorgas, além de gestão das licitações para concessão onerosa de frequências às operadoras de rede, e à Ancine (Agência Nacional do Cinema) para organizar e conduzir as licitações para outorga onerosa de programação a emissoras.

Observe-se que as agências reguladoras surgem em meados da década de 1990, com "a expansão do mercado liberal, representando uma consequência da redução do papel do Estado como operador executivo de serviços públicos" e visavam "desvincular 
da política a tarefa de decidir e regulamentar" determinados setores da economia (Aguillar, 2006, p. 205).

As Emendas Constitucionais 8 e 9, respectivamente de 15 de agosto e de 9 de novembro de 1995, e as inovações legislativas, como a lei 9.472, de 16 julho de 1997, que criou a Anatel, visavam destravar a "rigidez do modelo burocrático consagrado pela Constituição de 1988" (Pacheco, 2006, p. 525). Tratava-se, portanto, de uma política de transferência da exploração de determinados serviços públicos para o setor privado, reservando-se ao Estado a função regulamentadora (Meirelles, 2010, p. 376). A transferência incluiu como supostos objetivos despolitizar as decisões, garantir maior autonomia de gestão e "maior eficiência na implementação de políticas públicas e uma melhor prestação de serviços públicos" (Sampaio, 2013, p. 142), além de proteger os consumidores dos serviços subjacentes ao âmbito operacional das agências reguladoras (Pacheco, 2006).

A atribuição de competências similares para dois órgãos da administração pública não parece ser razoável, pois repetiria o problema atual de dualidade nas atribuições do Ministério das Comunicações e da Anatel, conforme Sundfeld (2004), referido acima.

Ademais, pode-se considerar que retirar a competência do Ministério das Comunicações para as outorgas não seria salutar, uma vez que as outorgas e extinções de concessões de radiodifusão demandam "uma decisão política e discricionária, envolvendo o Chefe do Executivo e o Congresso Nacional" (Sundfeld, 2004, p. 116). Transferir essas atividades para a Anatel, agência reguladora criada para alegadamente despolitizar a gestão das políticas de concessão, poderia reiterar a influência privada sobre o processo, o que poderia ampliar a concentração de mercado.

O capítulo 4 do anteprojeto de lei estabelece mecanismos para impedir a concentração dos meios de comunicação. A despeito da regra constitucional que proíbe o monopólio ou oligopólio dos meios de comunicação social (artigo $220,5^{\circ}$ ), a regulação dos mercados no Brasil através de legislação ordinária é muito tímida, não havendo limitações legais em relação à propriedade dos meios de comunicação (Sankievicz, 2011; Lima, 2012).

A única regulamentação infraconstitucional que trata do tema é o artigo 12, do Decreto-Lei 236 (1967), que impõe um número máximo de "1o estações radiodifusoras de som e imagem em todo território nacional, sendo no máximo 5 em VHF e 2 por Estado".

No anteprojeto, verifica-se a intenção de consolidar as poucas regras existentes na legislação brasileira, como o artigo 12 do Decreto-Lei 236/67, além de criar outras regras para se evitar a concentração no setor da comunicação, como é o caso da proibição de outorga para empresa que publique jornal diário, regra já prevista no artigo $2^{\circ}$, I, do projeto de lei 6.667/09, de autoria do deputado federal Ivan Valente.

Essas e outras regras previstas no texto do anteprojeto de lei determinarão a atuação dos órgãos reguladores, como serão os casos da Anatel e da Ancine, conforme mencionado acima, bem como do Conselho Administrativo de Defesa Econômica, autarquia federal responsável por fiscalizar a livre concorrência nos mercados.

O capítulo 5 objetiva regulamentar o artigo 221 da Constituição Federal, efetivando-se desta forma, pelo menos em termos legislativos, o texto constitucional e atingindo-se as metas do Programa Nacional de Direitos Humanos. 
Neste capítulo, duas importantes inovações jurídicas estão contempladas: direito de antena e regulamentação infraconstitucional do direito de resposta, incluindo-se neste caso o direito de resposta coletivo ou difuso.

O texto constitucional prevê o direito de resposta no artigo $5^{\circ}, \mathrm{V}$, no entanto, não há regulamentação da matéria por lei infraconstitucional desde 2009, quando o Supremo Tribunal Federal declarou na Arguição de Descumprimento de Preceito Fundamental - ADPF 130, proposta pelo Partido Democrático Trabalhista (PDT), a não recepção pela Constituição da lei 5.250/67, conhecida como Lei de Imprensa, que regulamentava esse direito, criando-se com a decisão uma lacuna jurídica3.

Também há a previsão do direito de antena no artigo 17 da Constituição, que no entanto fica restrito aos partidos políticos. O projeto de lei amplia esse direito para grupos sociais, o que poderá sustentar a diversidade de manifestações na radiodifusão, e está em sintonia com as recomendações adotadas em âmbito internacional, conforme o artigo 28 da Diretiva 2010/13 da União Europeia:

(...) qualquer pessoa singular ou colectiva, independentemente da sua nacionalidade, cujos legítimos direitos, nomeadamente a sua reputação e bom nome, tenham sido lesados na sequência de uma alegação incorrecta feita durante uma emissão televisiva, deve beneficiar do direito de resposta ou de medidas equivalentes. (Directiva, 2010, pp. 95/2)

Ainda segundo o artigo 28 da Diretiva 2010/13 "os Estados-Membros assegurarão que o exercício efectivo do direito de resposta ou de medidas equivalentes não seja dificultado pela imposição de termos ou condições excessivos" (Directiva, 2010/13, pp. 95/2).

O capítulo 6 do projeto de lei prevê a criação do Conselho Nacional de Políticas de Comunicação, além da possibilidade de Estados e municípios criarem "órgãos que auxiliem a efetivação dos princípios e objetivos da comunicação social eletrônica" (artigo 32, FNDC, 2014b). O dispositivo se coloca em linha com o contexto internacional de regulação da área, no qual se reconhece a necessidade de o poder público determinar regras claras de exploração da radiodifusão. A este respeito, a Comissão Europeia declara, na Diretiva 2010/13, considerando 14, seu compromisso com a criação e a manutenção de "um quadro coerente para o mercado interno dos serviços da sociedade da informação e dos serviços de comunicação social, através da modernização do enquadramento legal dos serviços audiovisuais" (Directiva, 2010/13, pp. 95/2).

Entre as atribuições do órgão regulador federal proposto pelo projeto de lei brasileiro, está a de "acompanhar e avaliar a execução das políticas públicas e da regulação do setor, de forma a proteger e promover os princípios e objetivos da comunicação social eletrônica" (FNDC, 2014b). Permanece em aberto, aqui, quais são os critérios a serem adotados para o acompanhamento e a avaliação indicados, omissão que pode gerar

\footnotetext{
${ }^{3} \mathrm{Em} 11$ de novembro de 2015 foi sancionada a lei 13.188 que dispõe sobre o direito de resposta. No entanto, a lei encontrava-se, no momento de conclusão deste artigo, sub judice tendo em vista ações diretas de inconstitucionalidade ajuizadas junto ao Supremo Tribunal Federal (ADI 5415 e 5436, as quais podem ser consultadas em http://www.stf.jus.br/portal/ peticaolnicial/ pesquisarPeticaolnicial.asp).
} 
resistência ao avanço do projeto. Se tais critérios forem definidos após a instalação do conselho, poderia ser esperada a criação de um contexto de atuação restrita para as emissoras, já que elas teriam apenas quatro entre 28 membros do órgão, segundo o artigo 29. Deve ser apontada, ainda, a existência de possíveis conflitos advindos da proposta de criação de um novo órgão regulador federal, já que a Constituição designa o Conselho de Comunicação Social como órgão auxiliar do Congresso Nacional para a tarefa.

Por fim, cabe indicar quatro aspectos não abrangidos adequadamente ou não tratados pelo projeto de lei, a saber: a) educação para mídia; b) autorregulação; c) colocação de produto ou merchandising; d) regulação de publicidade.

a) Educação para mídia. Em seu artigo 26, o texto determina, à comunicação eletrônica, a "adoção de políticas de fomento à leitura e prática de críticas de comunicação" (FNDC, 2014b). Aparentemente, trata-se de uma tímida menção às práticas de educação para mídia, que não especifica o significado da criticidade necessária como parâmetro para ações educativas em âmbitos de ensino formal e não formal.

Em contraste, a Diretiva 2010/13 é explícita sobre o propósito da educação para mídia no contexto europeu. "A 'educação para os media' visa as competências, os conhecimentos e a compreensão que permitem aos consumidores utilizarem os meios de comunicação social de forma eficaz e segura", segundo o considerando 47 (Directiva, 2010/13, p. 95/6). "As pessoas educadas para os media são capazes de fazer escolhas informadas, compreender a natureza dos conteúdos e serviços e tirar partido de toda a gama de oportunidades oferecidas pelas novas tecnologias das comunicações" (Directiva, 2010/13, p. 95/6). Embora ainda haja aqui alguma polissemia, nota-se um detalhamento desejável ao tema, que poderia ser adotado no Brasil.

b) Autorregulação. O projeto de lei renuncia à possibilidade de fixar a obrigação de as mídias contarem com mecanismos de autorregulação, que têm sido vistos como capazes de antecipar e prevenir parte significativa dos conflitos decorrentes de infrações éticas, trazendo eficiência ao sistema como um todo e proporcionando economia de recursos do órgão regulador, que assim poderia se concentrar em casos nos quais a autorregulação se revelasse falha ou omissa (Puppis, 2008).

A autorregulação não substitui a ação regulatória do poder público, mas a complementa, como ocorre na União Europeia, em que a Diretiva 2010/13 assinala o papel de os Estados-membros reconhecerem, "de acordo com as suas diversas tradições jurídicas, o papel que pode desempenhar uma auto-regulação eficaz como complemento dos mecanismos legislativos, judiciais e/ou administrativos existentes", de acordo com o considerando 44 (Directiva, 2010/13, p. 95/5). A complementaridade deve ser fixada em lei pelos países europeus, segundo a diretiva, gerando a chamada corregulação: "A co-regulação, na sua forma mínima, cria uma relação jurídica entre a auto-regulação e o legislador nacional" e "deverá permitir a possibilidade de intervenção estatal caso os seus objectivos não sejam atingidos", conforme considerando 42 (Directiva, 2010/13, p. 95).

c) Colocação de produto ou merchandising. Este é mais um aspecto de elevada relevância ignorado pelo projeto de lei da mídia democrática. Embora seja absolutamente comum no Brasil a prática publicitária chamada no Reino Unido e nos Estados Unidos 
de product placement, em Portugal de colocação de produto e no Brasil de merchandising, em que produtos de marcas à venda como bebidas, alimentos e roupas entram sorrateiramente em cenas de novelas, por exemplo, noutros pontos do planeta o quadro é distinto. A União Europeia indica que os países-membros não devem permiti-la. "A colocação de produto deveria, em princípio, ser proibida", embora sejam possíveis exceções que viabilizem a exibição de programas produzidos fora do território europeu, segundo o considerando 92 (Directiva, 2010/13, p. 95/10). Mas “o patrocínio e a colocação de produto deverão ser proibidos nos casos em que influenciem o conteúdo dos programas de um modo que afecte a responsabilidade e a independência editorial do fornecedor do serviço de comunicação social", conforme o considerando 93 (Directiva, 2010/13, p. 95/10). O princípio da separação deve ser respeitado nestes casos (considerando 81), baseado no suposto de que o público não pode ser levado a confundir-se entre um enredo ficcional e a realidade do apelo comercial da publicidade.

E, em uma tendência regulatória acentuada, "a colocação de temas está incluída nesses casos", considerando 93 (Directiva, 2010/13, p. 95/10). Ou seja, o chamado merchandising social no Brasil, em que as emissoras se veem no direito de incluir de forma velada mensagens políticas sob os enredos de novelas, deve ser proibida pelos países europeus, sob o argumento de que tanto produtos quanto ideias devem ser assumidos enquanto tais e tratados devidamente: os produtos são sujeitos às regras de regulação e autorregulação da publicidade, e as ideias devem ser manipuladas explicitamente em conformidade com os princípios de imparcialidade e exatidão jornalísticas.

d) Regulação de publicidade. No Brasil, predomina a autorregulação publicitária de bebidas com baixo teor alcoólico (até 13 graus Gay Lussac, segundo a lei 9294/96), ao passo que na União Europeia a Diretiva 2010/13 determina que os países-membros adotem medidas para restringir sua publicidade. "A publicidade televisiva (...) não deve associar o consumo de álcool a uma melhoria do rendimento físico ou à condução de veículos automóveis", segundo o artigo 22, "não deve criar a impressão de que o consumo de álcool favorece o sucesso social ou sexual" e "não deve sugerir que as bebidas alcoólicas são dotadas de propriedades terapêuticas ou têm efeito estimulante, sedativo ou anticonflitual" (Directiva, 2010/13, p. 95/19).

A publicidade infantil também é objeto da Diretiva 2010/13, que em seu artigo 9 considera "inadequada" a "comunicação comercial audiovisual (que) acompanhe ou esteja incluída em programas infantis, relativa a alimentos e bebidas que contenham nutrientes e substâncias (...) cuja presença em quantidades excessivas no regime alimentar não é recomendada" (Directiva, 2010/13, p. 95/16).

No Brasil, diante da ausência de leis específicas sobre o tema, o Conselho Nacional dos Direitos da Criança e do Adolescente (Conanda) publicou em março de 2014 a Resolução 163, segundo a qual "considera-se abusiva, em razão da política nacional de atendimento da criança e do adolescente, a prática do direcionamento de publicidade e de comunicação mercadológica à criança, com a intenção de persuadi-la para o consumo de qualquer produto ou serviço" (Conanda, 2014), utilizando artifícios típicos do universo infantil, como músicas, linguagem, adereços, personagens de desenho etc. A reação à Resolução 162 veio na forma de uma nota pública assinada pelas associações 
brasileiras de anunciantes, agências de publicidade, radiodifusores, editores de jornais e revistas, que afirma ser o Congresso Nacional o único foro legítimo para legislar sobre a matéria (ANER, 2014).

Frente a este impasse, o projeto de lei de mídia democrática teria um importante papel regulatório a cumprir. Ressalve-se, no entanto, que sua formulação pelo FNDC é anterior ao desdobramento liderado pelo Conanda. Isto indica como o rápido fluxo dos acontecimentos pode contribuir para relativizar a relevância de um projeto que dependa da coleta de 1,4 milhão de assinaturas para ingressar na pauta legislativa.

\section{Conclusões}

Este artigo examinou um dos produtos da dinâmica de organização dos movimentos sociais em defesa da democratização das comunicações no Brasil contemporâneo, qual seja, a campanha "Para expressar a liberdade", lançada em agosto em 2012 com o propósito de obter 1,4 milhão de assinaturas para sustentar um anteprojeto de lei de iniciativa popular a ser apresentado à Câmara dos Deputados com o objetivo de propor formas específicas de regulação da área.

Como parâmetros de apreciação do anteprojeto, foram empregados o arcabouço normativo presente na Constituição Federal e a referência internacional trazida pela Diretiva 2010/13, que regula a matéria no âmbito da União Europeia.

Os resultados da análise do projeto sugerem que as inovações propostas são oportunas e poderiam promover modificações necessárias ao cenário legal brasileiro, considerando-se os contextos normativos nacional e internacional.

No entanto, imprecisões conceituais, artigos capazes de gerar profundas transformações na relação de forças no mercado brasileiro das comunicações e desdobramentos posteriores à formulação do texto podem contribuir para gerar resistências ao avanço do projeto, que possivelmente por esta razão caminhe ainda lentamente em busca de apoio da sociedade brasileira.

As insuficiências indicadas podem ser enfrentadas nas arenas deliberativas do Congresso Nacional, uma vez concluída, mesmo que no longo prazo, a fase de coleta de assinaturas. $O$ anteprojeto se apresenta bem-sucedido ao trazer o tema ao escrutínio público e mobilizar setores diversos - o que, para os movimentos sociais situados em um país no qual a tradição de engajamento político se encontra ainda em construção, não é um passo que possa ter sua relevância ignorada.

\section{REFERÊNCIAS BIBLIOGRÁFICAS}

Adorno, S. (2010). História e desventura: o III Programa Nacional de Direitos Humanos. Novos Estudos, 86, 5-20.

Aguillar, F. H. (2006). Direito econômico: do direito nacional ao direito supranacional. São Paulo: Atlas.

Carlos, E. (2011). Contribuições da análise de redes sociais às teorias de movimentos sociais. Revista de Sociologia e Política, Curitiba, 19(39), 153-166. 
Cordeiro, P. J. F. (2004). Direito de autor e radiodifusão: um estudo sobre o direito de radiodifusão desde os primórdios até à tecnologia digital. Coimbra: Almedina.

Coutinho, D. R. (2013). O direito nas políticas públicas. In E. Marques \& C. A. P. de Faria (Eds.), A Política Pública como Campo Multidisciplinar (pp. 181-200). São Paulo: Unesp; Rio de Janeiro: Fiocruz.

Dantas, M. \& Neiva, A. (2014). Da Confecom ao PNBL: balanço e perspectivas do debate sobre Comunicações no Brasil. In M. Dantas (Ed.), Avances en los Procesos de Democratización de la Comunicación en America Latina (pp. 167-190). Buenos Aires: CLACSO.

Gohn, M. G. (2014). A sociedade brasileira em movimento: vozes das ruas e seus ecos políticos e sociais. Caderno $\mathrm{CRH}, 27(71), 431-441$.

Leal Filho, L. (2006). TV sob controle: a resposta da sociedade ao poder da televisão. São Paulo: Summus.

Lima, V. A. (2011). Regulação das comunicações: história, poder e direitos. São Paulo: Paulus.

Lima, V. A. (2012). Política de comunicações: um balanço dos governos Lula [2003-2010]. São Paulo: Publisher Brasil.

Lima, V. A. (2013). Conselhos de comunicação social: a interdição de um instrumento da democracia participativa. Brasília: FNDC.

Lima, V. A. (2014). Para garantir o direito à comunicação: a Lei Argentina, o Relatório Leveson (Inglaterra) e o HLG da União Europeia. São Paulo: Fundação Perseu Abramo.

Meirelles, H. L. (2010). Direito administrativo brasileiro. São Paulo: Malheiros.

Mendel, T. \& Salomon, E. (2011a). O ambiente regulatório para a radiodifusão: uma pesquisa de melhores práticas para os atores-chave brasileiros. Série Debates Cl Unesco, 7, 1-78. Retirado de http://unesdoc. unesco.org/images/o019/001916/191622por.pdf.

Mendel, T. \& Salomon, E. (2011b). Liberdade de expressão e regulação da radiodifusão. Série Debates Cl Unesco, 8, 1-19. Retirado de http://unesdoc.unesco.org/images/oo19/oo1916/191623por.pdf.

Moraes, D. (2014). Batalhas pela diversidade: o que aprender com as experiências latino-americanas. In V. A. Lima, J. Guimarães \& A. P. Amorim (Eds.), Em Defesa de uma Opinião Pública Democrática: Conceitos, Entraves e Desafios (pp. 219-237). São Paulo: Paulus.

Nunes, J. H. (2013). Interacionismo simbólico e movimentos sociais: enquadrando a intervenção. Sociedade e Estado, 28(2), 257-277.

Pacheco, R. S. (2006). Regulação no Brasil: desenho das agências e forma de controle. RAP. Revista Brasileira de Administração Pública, 40(4), 523-543.

Pieranti, O. P. (2006). Políticas para a mídia: dos militares ao governo Lula. Lua Nova, 68, 91-121.

Pieranti, O. P. \& Martins, P. E. M. (2008). Políticas públicas para as comunicações no Brasil: adequação tecnológica e liberdade de expressão. RAP. Revista Brasileira de Administração Pública, 42(2), 303-325.

Piovesan, F. (2010). A constitucionalidade do PNDH-3. Revista Direitos Humanos, 5, 12-16.

Puppis, M. (2008). National media regulation in the era of free trade: the role of global media governance. European Journal of Communication, 23(4), 405-424.

Ramos, M. C. O. \& Santos, S. (Eds.) (2007). Políticas de comunicação: buscas teóricas e práticas. São Paulo: Paulus. 
Sampaio, P. S. (2013). A independência real das agências reguladoras no Brasil. Revista de Direito, Estado e Telecomunicações, 5(1), 135-174.

Sankievicz, A. (2011). Liberdade de expressão e pluralismo: perspectivas de regulação. São Paulo: Saraiva.

SEEP, Secretaria Especial de Editoração e Publicações. Secretaria de Anais. (2008). Assembleia Nacional Constituinte - 20 anos: Atas da Comissão da Família, da Educação, Cultura e Esportes, da Ciência e Tecnologia e da Comunicação. Brasília.

Simis, A. (2010). Conselho de comunicação social: uma válvula para o diálogo ou para o silêncio? Revista Brasileira de Ciências Sociais, 25(72), 59-174.

Sundfeld, C. A. (2004). A regulação das telecomunicações: papel atual e tendências futuras. In M. Figueiredo (Ed.), Direito e Regulação (pp. 11-122). São Paulo: Malheiros.

\section{OUTRAS REFERÊNCIAS}

ANER, Associação Nacional de Editores de Revistas et al. (2014). Nota pública: publicidade infantil. Retirado de http://aner.org.br/nota-publica-publicidade-infantil/

Brasil (2010). Constituição da República Federal. Brasília, DF. Retirado de http://www.stf.jus.br/repositorio/ cms/portalStfInternacional/portalStfSobreCorte_en_us/anexo/constituicao_ingles_3ed2010.pdf

Conanda, Conselho Nacional dos Direitos da Criança e do Adolescente (2014). Resolução 163, de 13 de março de 2014. Retirado de https://www.legisweb.com.br/legislacao/?id=268725.

Constituição Federal de 05 de outubro de 1988, República Federativa do Brasil. Retirado de http://www. planalto.gov.br/ccivil_03/Constituicao/Constituicao.htm

Decreto-lei 236, de 28 de fevereiro de 1967, República Federativa do Brasil. Retirado de http://www.planalto. gov.br/ccivil_03/decreto-lei/Delo236.htm

Decreto 7.037, de 21 de dezembro de 2009, República Federativa do Brasil, que aprova o Programa Nacional de Direitos Humanos - PNDH-3. Retirado de http://www.planalto.gov.br/ccivil_03/_Ato20072010/2009/Decreto/D7037.htm

Directiva 2010/13/UE do Parlamento Europeu e do Conselho, de 10 de março de 2010. Retirado de http:// www.gmcs.pt/ficheiros/pt/directiva-201013ue.pdf

FNDC, Fórum Nacional pela Democratização da Comunicação. (2012). Apresentação. Retirado de http:// www.paraexpressaraliberdade.org.br/index.php/ quem-somos/apresentacao.

FNDC, Fórum Nacional pela Democratização da Comunicação. (2014a). Quem somos. Retirado de http:// www.fndc.org.br/forum/quem-somos/.

FNDC, Fórum Nacional pela Democratização da Comunicação. (2014b). Projeto de lei. Retirado de http:// www.paraexpressaraliberdade.org.br/index.php/ 2013-04-30-15-58-11.

Intervozes, Coletivo Brasil de Comunicação Social. (2007). A sociedade Ocupa a TV: O Caso Direitos de Resposta e o Controle Público da Mídia. São Paulo. Retirado de http://www.intervozes.org.br/arquivos/ interlivoosasotvdr.

Intervozes, Coletivo Brasil de Comunicação Social. (2008). Dossiê Violações do Direito à comunicação. Brasília, DF. 
Ministério das Comunicações. (2010). Caderno da $1^{\text {a }}$ Conferência Nacional de Comunicação. Secretaria de Comunicação Social da Presidência da República.

TSE, Tribunal Superior Eleitoral. (2014). Estatísticas de eleitorado / Evolução do eleitorado. Retirado de http://www.tse.jus.br/eleitor/estatisticas-de-eleitorado/evolucao-do-eleitorado.

Unesco (2010). Indicadores de desenvolvimento da mídia: marco para a avaliação do desenvolvimento dos meios de comunicação. Brasília. Retirado de http://unesdoc.unesco.org/ images/0016/001631/163102por.pdf

\section{NOTAS BIBLIOGRÁFICAS}

Danilo Rothberg é livre-docente em Sociologia da Comunicação pela Unesp (Universidade Estadual Paulista). É professor do Departamento de Ciências Humanas da Faculdade de Arquitetura, Artes e Comunicação (Faac) da Unesp e pesquisador visitante em King's College London e Open University (Reino Unido).

E-mail: danroth@uol.com.br

Universidade Estadual Paulista - UNESP

Faculdade de Arquitetura, Artes e Comunicação - FAAC, Departamento de Ciências Humanas

Av. Luiz Edmundo Carrijo Coube, 14-01

Bauru-SP, 17033-360, Brasil

Carlo José Napolitano é doutor em Sociologia pela Faculdade de Ciências e Letras da Unesp/Araraquara, Mestre em Direito pelo Programa de Pós-graduação da Instituição Toledo de Ensino de Bauru. Docente do Departamento de Ciências Humanas e do Programa de Pós-Graduação em Comunicação da Faculdade de Arquitetura, Artes e Comunicação, da Universidade Estadual Paulista (Unesp). Pós-doutorando no Departamento de Direito do Estado, da Faculdade de Direito da Universidade de São Paulo.

E-mail: carlonapolitano@faac.unesp.br

Universidade Estadual Paulista - UNESP

Faculdade de Arquitetura, Artes e Comunicação - FAAC, Departamento de Ciências Humanas

Avenida Luiz Edmundo Carrijo Coube, 14-01, Vargem Limpa

Bauru-SP, 17033-360, Brasil

Tatiana Stroppa é doutoranda em Direito e Mestre em Direito pelo Programa de Pós-graduação stricto sensu - Instituição Toledo de Ensino (2006). Atualmente é professora de Direito Constitucional e de Direito Processual Constitucional do Curso de Direito e da Pós-Graduação Lato Sensu do Centro Universitário de Bauru (ITE-SP). Advogada.

Email: tatianastroppa@hotmail.com.

Centro Universitário de Bauru (ITE) - Praça IX de Julho, 1-51, Vila Pacífico

Bauru-SP, 17050-790, Brasil 


\section{* Submetido: 13-03-2016}

* Aceite: 12-04-2016 